\title{
Neuronal Circuit Remodeling in the Contralateral Cortical Hemisphere during Functional Recovery from Cerebral Infarction
}

\author{
Yusuke Takatsuru, ${ }^{1,3}$ Dai Fukumoto, ${ }^{5}$ Miki Yoshitomo, ${ }^{1}$ Tomomi Nemoto, ${ }^{2,3,4}$ Hideo Tsukada, ${ }^{5}$ \\ and Junichi Nabekura ${ }^{1,3,4}$ \\ ${ }^{1}$ Division of Homeostatic Development and ${ }^{2}$ Supportive Center for Brain Research, National Institute for Physiological Sciences, Okazaki, Aichi 444-8585, \\ Japan, ${ }^{3}$ Core Research for Evolutional Science and Technology, Japan Science and Technology Agency, Kawaguchi 332-0012, Japan, ${ }^{4}$ The Graduate \\ University for Advanced Studies (SOKENDAI), Hayama, Kanagawa 240-0193, Japan, and ${ }^{5}$ Central Research Laboratory, Hamamatsu Photonics, \\ Hamamatsu, Shizuoka 434-8601, Japan
}

Recent advances in functional imaging of human brain activity in stroke patients, e.g., functional magnetic resonance imaging, have revealed that cortical hemisphere contralateral to the infarction plays an important role in the recovery process. However, underlying mechanisms occurring in contralateral hemisphere during functional recovery have not been elucidated. We experimentally induced a complete infarction of somatosensory cortex in right hemisphere of mice and examined the neuronal changes in contralateral (left) somatosensory cortex during recovery. Both basal and ipsilateral somatosensory stimuli-evoked neuronal activity in left (intact) hemisphere transiently increased $2 \mathrm{~d}$ after stroke, followed by an increase in the turnover rate of usually stable mushroom-type synaptic spines at 1 week, observed by using two-photon imaging in vivo. At 4 weeks after stroke, when functional recovery had occurred, a new pattern of electrical circuit activity in response to somatosensory stimuli was established in intact ipsilateral hemisphere. Thus, the left somatosensory cortex can compensate for the loss of the right somatosensory cortex by remodeling neuronal circuits and establishing new sensory processing. This finding could contribute to establish the effective clinical treatments targeted on the intact hemisphere for the recovery of impaired functions and to achieve better quality of life of patients.

\section{Introduction}

Survivors of focal brain ischemia need chronic care for recovery and/or compensation of the impaired functions, such as speech and various sensory and motor functions that had been operated by the focal ischemic core. Recent advances in functional imaging of human brain activity in stroke patients, e.g., positron emission tomographic and functional magnetic resonance imaging, reveal that cortical hemisphere contralateral to the infarction plays an important role in this recovery process (Calautti and Baron, 2003; Bütefisch et al., 2006; Crosson et al., 2007; Ward, 2007). Reorganization of the activity to the nondominant righthemisphere homolog of Wernicke's area has been reported in the

Received April 6, 2009; revised May 27, 2009; accepted July 6, 2009.

This work was supported by a Core Research for Evolutional Science and Technology grant from the Japan Science and Technology Agency and Grant-in-Aid for Scientific Research (B) (19390055) from the Japan Society for the Scientific of Sciences (JSPS) to J.N. and Grant-in-Aid for Scientific Research (B) (19790184) from JSPS to Y.T. We are grateful to Dr. Takeharu Kakiuchi and other members of Central Research Laboratory, Hamamatsu Photonics Co. Ltd., for supporting the autoradiography experiment. We thank Dr. A. Moorhouse (The University of New South Wales, Sydney, Australia) for help with the English editing.

The authors declare no competing financial interests.

Correspondence should be addressed to Prof. Junichi Nabekura, Department of Developmental Physiology, National Institute for Physiological Sciences, 38 Nishigonaka Myodaiji, Okazaki, Aichi 444-8585, Japan. E-mail: nabekura@nips.ac.jp.

Y. Takatsuru's present address: Department of Integrative Physiology, Gunma University Graduated School of Medicine, Maebashi, Gunma 371-8511, Japan.

DOI:10.1523/JNEUROSCI.1638-09.2009

Copyright $\odot 2009$ Society for Neuroscience $\quad$ 0270-6474/09/2910081-06\$15.00/0 process of recovery from aphasia (Weiller et al., 1995). There is also clinical evidence showing that the postischemic reorganization occurring in somatosensory system of the contralesional (intact) hemisphere plays an important role for compensation for impaired functions (Chollet et al., 1991; Cao et al., 1998). During recovery from the stroke, hand finger tapping activates ipsilateral somatosensory cortex (SSC) unaffected (Cramer et al., 1997). Thus, the underlying mechanism of this compensation occurring in the intact hemisphere is important for optimizing the functional recovery of human stroke patients (Calautti and Baron, 2003).

Also in animal models of stroke, experimental infarctions at unilateral SSC and motor cortex result in functional and structural changes in the remaining intact hemisphere. Infarction in the SSC changes the receptive field at the contralateral SSC at 1 week (1W) after stroke (Reinecke et al., 2003). After the recovery of motor function impaired by cerebral infarction, the topographic map is reorganized and the dendritic branching of layer $\mathrm{V}$ pyramidal neurons is increased in contralateral motor cortex (Gonzalez et al., 2004), which is enhanced by early onset of rehabilitative tasks in mice (Biernaskie et al., 2004). These results suggest that the change of neuronal circuits could be introduced in contralateral hemisphere to the infarction during the functional recovery.

In addition to increased evidence of the contribution of contralateral (intact) hemisphere to functional recovery after stroke, 
A
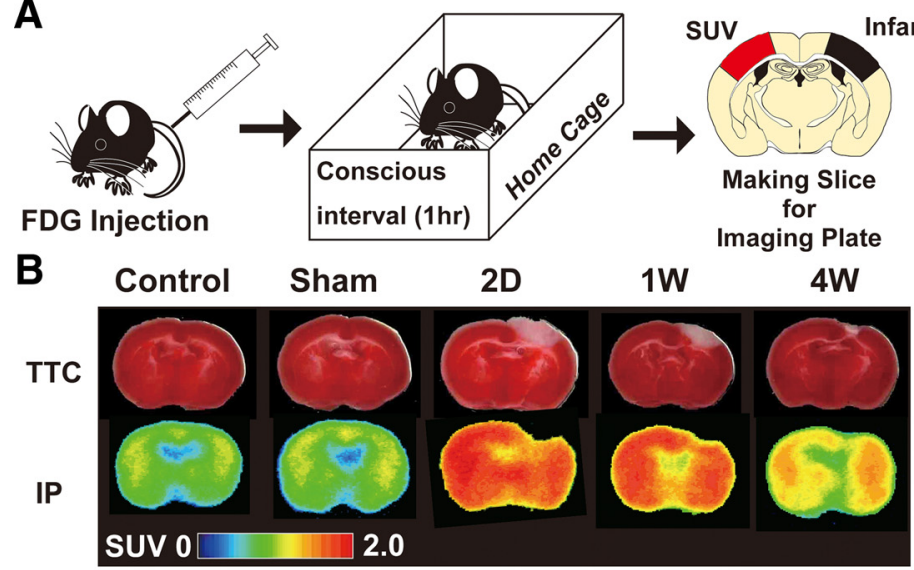

D

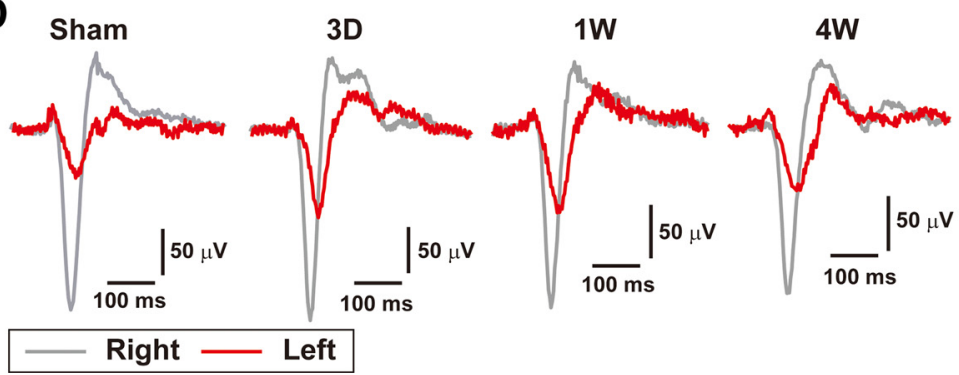

C

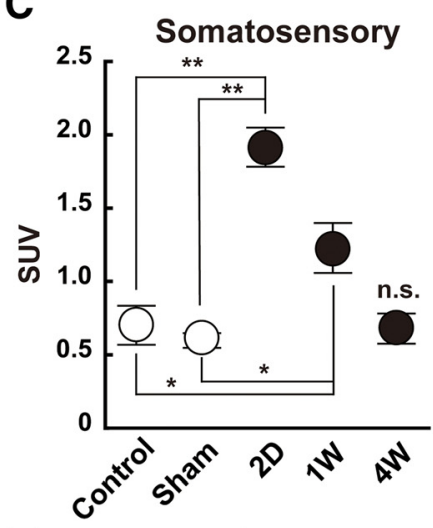

E

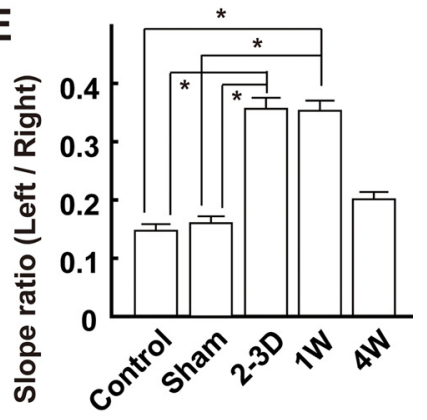

Figure 1. Neuronal activity in the left hemisphere SSC was increased during the first week following an infarct in the right SSC. A, Schematic description of the experimental protocol used for autoradiography (see supplemental Methods, available at www.jneurosci.org as supplemental material). B, Typical images of the TTC stain and imaging plate (IP) of brain slices. The autoradiography counts from the left SSC in IP images were expressed as SUV. C, Graph showing the SUV of control, sham-operated, and $2 \mathrm{~d}$, 1W, and 4W mice after stroke. The SUV was significantly increased at $2 \mathrm{~d}$ and $1 \mathrm{~W}$. Statistical comparison was performed by Holm test. D, Typical averaged CFPs recorded in the left SSC in control, sham, and $3 \mathrm{~d}, 1 \mathrm{~W}$, and 4W mice. The gray lines represent the CFP induced by stimulation of the right limbs and the red lines represent that of the left limb (the average of 5-15 traces). E, Graph showing the averaged relative CFP slope (left/right limb CFP) in each mouse. The relative slope was significantly increased in mice at first week after stroke. Statistical comparison was performed by Bonferroni test. ${ }^{*} \alpha=0.05 ;{ }^{* *} \alpha=0.01$.

however, the neuronal and circuit's remodeling occurring in the intact hemisphere is less understood. Recent intense studies using in vivo two-photon laser microscopy have revealed the neuronal circuits remodeling, e.g., spine turnover (Brown et al., 2007) and glial contribution to synapse remodeling (Wake et al., 2009) in the damaged hemisphere. Therefore, this technique will also contribute to understanding of the change in contralateral (intact) hemisphere to the infarction during the functional recovery.

Here, we show the remodeling of neuronal circuits and somatosensory processing occurring in the contralateral (intact) SSC during the functional recovery in mice receiving cerebral ischemic infarction.

\section{Materials and Methods}

This study was approved by the Animal Research Committee of the National Institutes of Natural Sciences. All efforts were made to minimize the suffering and number of animals used in this study. More detailed information can be found in the supplemental Methods (available at www.jneurosci.org as supplemental material).

Photothrombosis. Photoactivation of Rose Bengal solution induces clotting and thrombosis. To photoactivate the right SSC (1-3 mm lateral and -1.5 to $1 \mathrm{~mm}$ anterior to bregma), a $2 \times 2 \mathrm{~mm}$ region of skull was thinned to $50 \%$ of original thickness using a high-speed drill. Mice were given an injection of $2 \%(\mathrm{w} / \mathrm{v})$ solution of Rose Bengal ( $16 \mathrm{mg} / \mathrm{kg}$, i.v.) in $0.9 \% \mathrm{NaCl}$. To initiate photoactivation, the thinned region of the skull was illuminated with a mercury lamp of green light (530-550 $\mathrm{nm}, 17 \mathrm{~mW}$; focused with $4 \times$ objective lens, numerical aperture 0.13 ) for $15 \mathrm{~min}$.

Autoradiography. Autoradiography using ${ }^{18} \mathrm{~F}$-fluorodeoxyglucose (FDG) uptake was measured in control, sham-operated, and stroke mice ( $2 \mathrm{~d}, 1$ week, and 4 weeks after induction of infarction). The standardized glucose uptake value (SUV) was calculated, which is a decay-corrected measurement of average radioactivity per unit volume of tissue.

Electrophysiology. Cortical field potential (CFP) was induced by fourlimb vibrotactile stimulation $(100 \mathrm{~ms}, 140 \mathrm{~Hz})$ using a custom-made mechanical limb manipulator incorporating a vibration motor. The CFP was recorded using sharpened tungsten electrodes (125 $\mu \mathrm{m}$ diameter), amplified (ER-91, NeuroData), bandpass filtered (1-10 kHz), and sent to an analog-to-digital converter (PowerLab/4ST). The electrode was orientated in the coronal plane with a $15-20^{\circ}$ lateral angle.

Behavioral tests. Control somatosensory function and recovery of function following the infarct were measured using tape test and von Frey test. Preoperated control in each mouse was obtained $3 \mathrm{~d}$ before surgery/ stroke, and mice were then retested at $2 \mathrm{~d}$ and 1, 2, and 4 weeks after surgery. CNQX was injected 2 weeks after surgery for both shamoperated and infarcted mice.

Spine imaging and structural analysis. To avoid possible changes to dendritic structure induced by opening the skull, in vivo two-photon images of the dendrites were taken using the thinned-skull imaging window.

\section{Results}

We first measured the effect of a cerebral infarction of the right SSC on the basal activity of the left SSC in resting conscious mice using radiolabeled glucose ( $\left.{ }^{18} \mathrm{~F}-\mathrm{FDG}\right)$ uptake and autoradiography (supplemental data, available at www.jneurosci.org as supplemental material; Fig. $1 A$ ). As shown in Figure 1, $B$ and $C$, SUV of the left hemisphere significantly increased $\left(F_{(4,26)}=14.46 ; p<\right.$ 0.001 by Holm test) compared with the sham-operated $(0.62 \pm$ $0.03 \mathrm{MBq} / \mathrm{g})$ and control $(0.71 \pm 0.13 \mathrm{MBq} / \mathrm{g})$ mice at $2 \mathrm{~d}$ after stroke $\left(1.92 \pm 0.14 \mathrm{MBq} / \mathrm{g}\right.$; compared with control, $t_{(10)}=5.97$, $p=0.000003$; compared with sham, $\left.t_{(8)}=5.73, p=0.000005\right)$ 
A

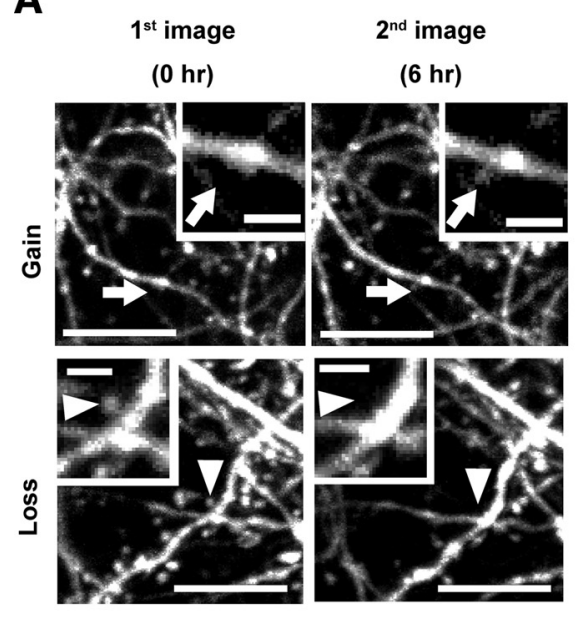

B

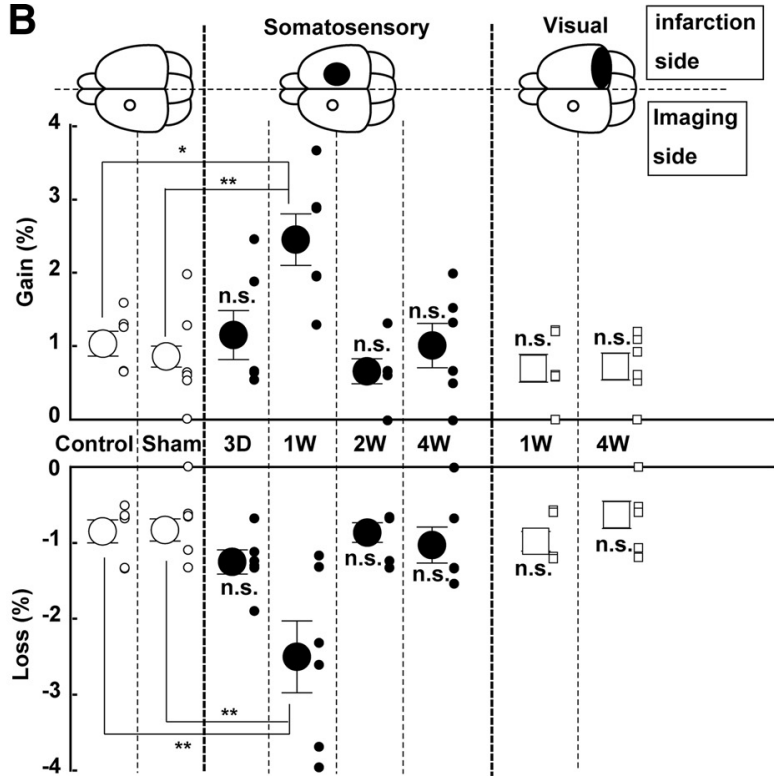

Figure 2. Turnover rate of mushroom spines in the left hemisphere SSC was specifically increased at 1 week after infarction in the right SSC. A, Typical in vivo images of dendritic spines in the left SSC taken during the first and second imaging sessions ( $6 \mathrm{~h} \mathrm{later)} \mathrm{in} \mathrm{control} \mathrm{mice.} \mathrm{The} \mathrm{arrows} \mathrm{in} \mathrm{the} \mathrm{upper} \mathrm{panels} \mathrm{show} \mathrm{the} \mathrm{appearance} \mathrm{of} \mathrm{a} \mathrm{new} \mathrm{spine} \mathrm{(gained} \mathrm{spine),} \mathrm{while} \mathrm{the} \mathrm{arrowheads} \mathrm{in} \mathrm{the}$ lower panels indicate a spine that was lost. Scale bars, $10 \mu \mathrm{m}$. The insets show higher-magnitude images (scale bars, $2 \mu \mathrm{m}$ ). $\boldsymbol{B}$, Plot of the percentage of mushroom spines that were gained (upper panel) and lost (lower panel) in each mouse during the $6 \mathrm{~h}$ between imaging sessions. Note that significantly greater gain and loss of spines was observed at $1 \mathrm{~W}$. An infarction in the right visual cortex did not change the turnover rate of mushroom spines in the left SSC. Small open and closed circles or squares represent data from each mouse $(n=6)$, while the larger circles and squares represent the averaged data. Error bars represent \pm SEM. n.s. indicates not significantly different compared with both control and sham by Bonferroni test.

and $1 \mathrm{~W}$ after stroke $(1.22 \pm 0.18 \mathrm{MBq} / \mathrm{g}$; compared with control, $t_{(12)}=2.73, p=0.0011$; compared with sham, $t_{(10)}=2.82, p=$ 0.0009). At $4 \mathrm{~W}$ after the stroke, the SUV had returned to control levels $(0.69 \pm 0.09 \mathrm{MBq} / \mathrm{g})$.

As a more specific measure of neuronal activity, we measured the cortical field potential in the (intact) left SSC in vivo evoked by vibrotactile stimulation of the right (contralateral: common sensory processing pathway) or left (ipsilateral, uncommon pathway) limbs. The field potential reflects the summed discharge of postsynaptic neurons activated by the stimulus and was quantified by measuring its slope, which is highly correlated with peak amplitude (Lomo, 1971). As shown in Figure $1 D$ and supplemental Figure S1 (available at www.jneurosci.org as supplemental material), the stimulation of the contralateral (right) limbs evoked a larger response in the left SSC than that evoked by stimulation of the ipsilateral (left) limb with lower failure rate even in stroke mice (CFP: $F_{(1,96)}=98.86 ; p<0.0001$; failure rate: $F_{(1,96)}=92.86 ; p<0.0001$ by two-way ANOVA). However at $2-3$ $\mathrm{d}$ and $1 \mathrm{~W}$ after a cerebral infarct in the right SSC, the relative slope of the ipsilateral response became significantly larger than observed in control and sham-operated mice (Fig. 1E; supplemental Table S2, available at www.jneurosci.org as supplemental material) $\left(F_{(4,48)}=4.82 ; p=0.002\right.$ by Bonferroni test $)$.

Therefore a focal cortical infarction results in a rapid and transient increase both in the basal activity of the intact contralateral cortex and in the relative response to ipsilateral somatosensory stimulation, suggesting that the sensory response was now being more represented in the ipsilateral SSC.

We next investigated any structural rearrangements in neurons that may accompany the changes in the neuronal activity in the (intact) left SSC using high-resolution in vivo two-photon imaging. The turnover rate of mushroom-type spines in the dendrites of the pyramidal neurons in the intact left cortex increased at $1 \mathrm{~W}$ following an infarct to the right SSC (Fig. 2; supplemental Fig. S2 and Methods, available at www.jneurosci.org as supple- mental material). Mushroom spines are stable structures (Grutzendler et al., 2002; Trachtenberg et al., 2002) in the noninjured brain, and the incidences of formation and loss of mushroom spines during $6 \mathrm{~h}$ (i.e., turnover rate) in the left SSC of control or sham mice were both $\sim 1 \%$ of the total spines observed (Fig. 2 B). A similar turnover rate of mushroom spines was seen at $3 \mathrm{~d}, 2 \mathrm{~W}$, and $4 \mathrm{~W}$ after right SSC stroke (Fig. 2 B; supplemental Table S3, available at www.jneurosci.org as supplemental material). However, at $1 \mathrm{~W}$, there was a significant increase (gain: $F_{(5,30)}=5.29$; $p=0.0013$; loss: $F_{(5,30)}=6.91 ; p=0.0002$ by Bonferroni test) in mushroom spine turnover rate (Fig. 2 B; supplemental Table S3, available at www.jneurosci.org as supplemental material) (gain: $2.45 \pm 0.35 \%$, compared with control, $t_{(10)}=3.61, p=0.0011$; compared with sham, $t_{(10)}=4.05, p=0.0003$; loss: $-2.50 \pm$ $0.47 \%$, compared with control, $t_{(10)}=4.75, p=0.00005$; compared with sham, $\left.t_{(10)}=4.79 ; p=0.00004\right)$. In contrast, an infarction introduced in the visual cortex of the right hemisphere had no effect on the turnover rate of mushroom spines in the left SSC, even at $1 \mathrm{~W}$ (Fig. 2; supplemental Table S3, available at www. jneurosci.org as supplemental material). These results indicate a transient plasticity of dendritic spines occurring at homologous areas of intact hemisphere during a limited period following cerebral infarction.

The above results indicate the plasticity at the level of individual neurons and synapses. To examine whether there is an associated plasticity of the neuronal circuits in the left hemisphere SSC following a stroke in the right hemisphere SSC, we used the technique of current source density (CSD) measurements from the surface of the cortex through to a depth of $\sim 700 \mu \mathrm{m}$ (current sink/source) (see supplemental Fig. S4 and Methods, available at www.jneurosci.org as supplemental material). As shown for the averaged CSD maps in Fig. 3B, tactile stimulation of the right (contralateral) limbs induced a specific pattern of sinks/source in the left SSC of control/sham-operated mice and mice with an infarction of the right SSC (Fig. 3B). Stimulation of the left (ipsi- 

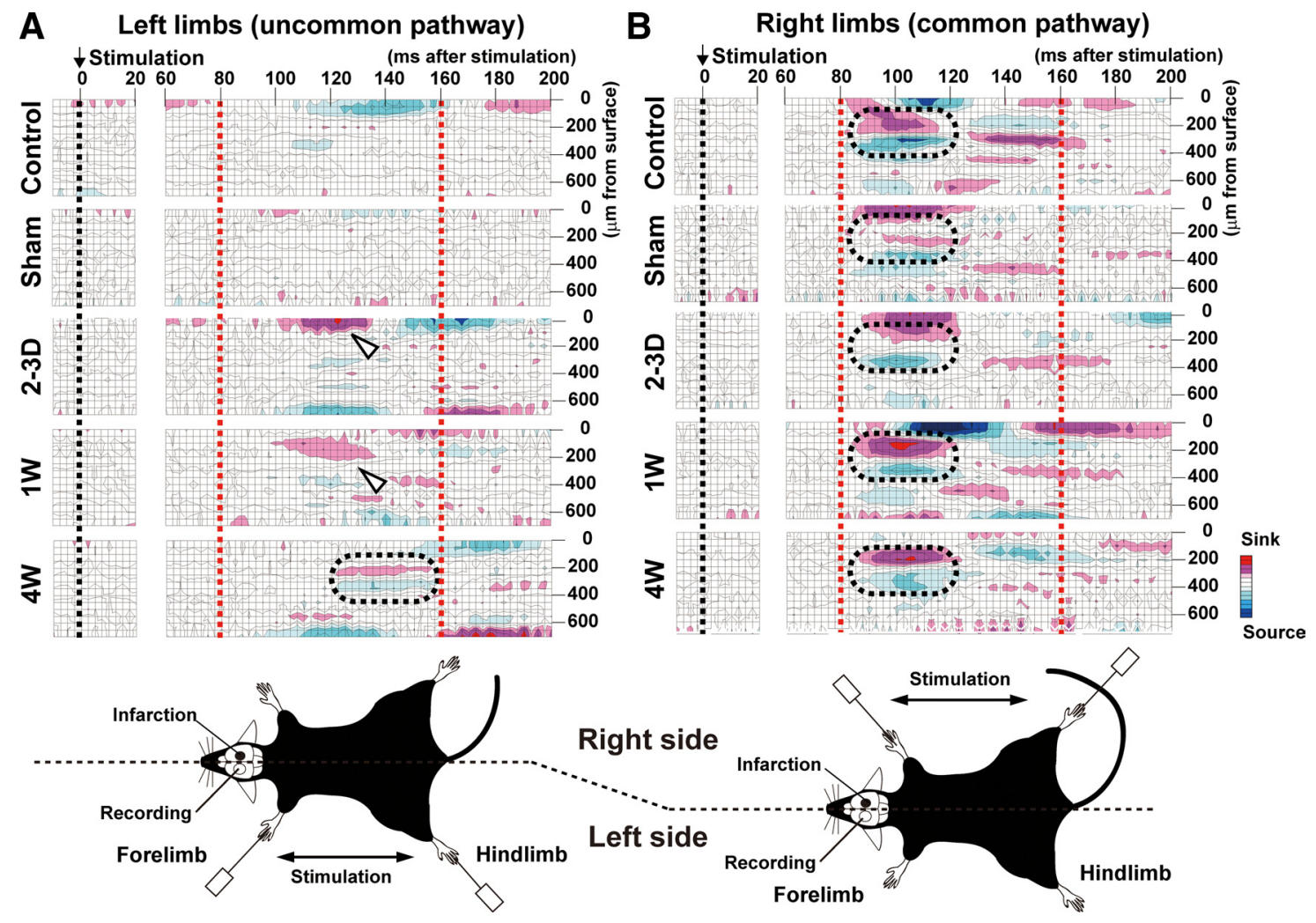

Figure 3. A focal infarction in the right SSC induced the appearance of new neuronal circuits in the left SSC. $A, B$, CSD maps of responses in the left SSC in response to stimulation of the left limbs $(\boldsymbol{A})$ or right limbs $(\boldsymbol{B})$. CSD measurements were obtained between 0 and $700 \mu \mathrm{m}$ from the brain surface. The dashed circles represent the spatial and temporal distribution of the strongest sink and sources of the CSD. The strong neuronal circuit responses to right limb (contralateral) stimulation were observed through the entire period of recovery. The strong responses in control and sham mice to left limb (ipsilateral) stimulation were not apparent. Note that the development of neuronal circuit activity in response to left limb stimulation in stroke mice became particularly distinct at 4W. The CSD pattern generated was similar in spatial distribution to the response to right limb stimulation, but with an increased latency.

lateral) limbs in control and sham mice did not induce such a distinct CSD map in the left SSC (Fig. 3A). In contrast, mice with a stroke induced in the right SSC showed a distinct CSD pattern in the left SSC in response to sensory stimulation of the left (ipsilateral) limbs (Fig. $3 A$ ). The region corresponding to the sink of the CSD (Fig. $3 A$, arrowheads) gradually shifted to deeper cortical areas at 2-3 d and $1 \mathrm{~W}$ after stroke. At $4 \mathrm{~W}$ after stroke, a time when functional recovery is apparent (see below), the CSD map in response to left limb stimulation was similar in spatial distribution to that induced by right limb stimulation, but was delayed in its latency (Fig. 3, dashed circle). This result indicates that the infarction in right SSC has induced new neuronal circuit activity in the left SSC in response to stimulation of the left limbs.

To correlate the above changes in neuronal activity and structure to any functional consequences, we examined the responses of both the right (ipsilateral) and left (contralateral) paws using "tape test" and the withdrawal response to application of different tensions to the hindlimb using von Frey hairs (see supplemental Methods, available at www.jneurosci.org as supplemental material). An infarction in the right SSC resulted in an initial decline in somatosensory function in response to tape test $\left(F_{(9,90)}=2.97\right.$, $p=0.004)$ and von Frey test $\left(F_{(9,90)}=11.99 ; p<0.001\right)$ applied to the left (contralateral) paws, without disrupting sensory responses arising from the right (ipsilateral) paws (Fig. 4A, B, E, F; see also supplemental Tables S4, S5, available at www.jneurosci. org as supplemental material). This somatosensory dysfunction was evident at $2 \mathrm{~d}$ before subsequent functional recovery. At no stage was motor function evident for either the right or left side limbs (Fig. 4C,D). To examine the contribution of the (intact) left
SSC to the functional recovery, we injected CNQX, a potent antagonist of AMPA/kainate-type glutamate receptors (Honoré et al., 1988), into the left cortical hemisphere in sham and stroke mice. CNQX impaired sensory responses to von Frey hairs applied to the right paw in both sham $\left(F_{(5,24)}=7.16 ; p=0.0003\right)$ and infarct $\left(F_{(5,30)}=9.46 ; p<0.0001\right)$ mice (Fig. $\left.4 H\right)$. CNQX significantly $\left(F_{(5,30)}=7.38 ; p=0.0001\right)$ impaired sensory responses applied to the left (ipsilateral) paw only in mice with right hemisphere infarction, but not in the sham-operated mice (Fig. $4 G)$. These results reveal that when the right hemisphere is infarcted, sensory responses from the left paw become processed in the intact left (ipsilateral) SSC.

\section{Discussion}

In the present study, the increase in basal neuronal activity and the amplitude of electrical responses to ipsilateral peripheral stimulation in intact SSC (left) was apparent at 2-3 d after the experimental infarction of the right SSC (Fig. 1). The strokerelated changes, e.g., prolonged EPSPs (Luhmann et al., 1995; Neumann-Haefelin et al., 1995) and a decrease in GABAergic inhibition (Schiene et al., 1996; Que et al., 1999), promote the circuit's excitability and facilitate the induction of synaptic plasticity, resulting in producing long-lasting alterations in the network properties of adjacent and connected cortical regions to the damaged area (Carmichael, 2003). Indeed, the brain activity, especially the contralateral SSC, was increased in the first week after stroke (Fig. 1).

At a structural level, the focal infarction produced a transient and region-specific increase in turnover of mushroom-type den- 


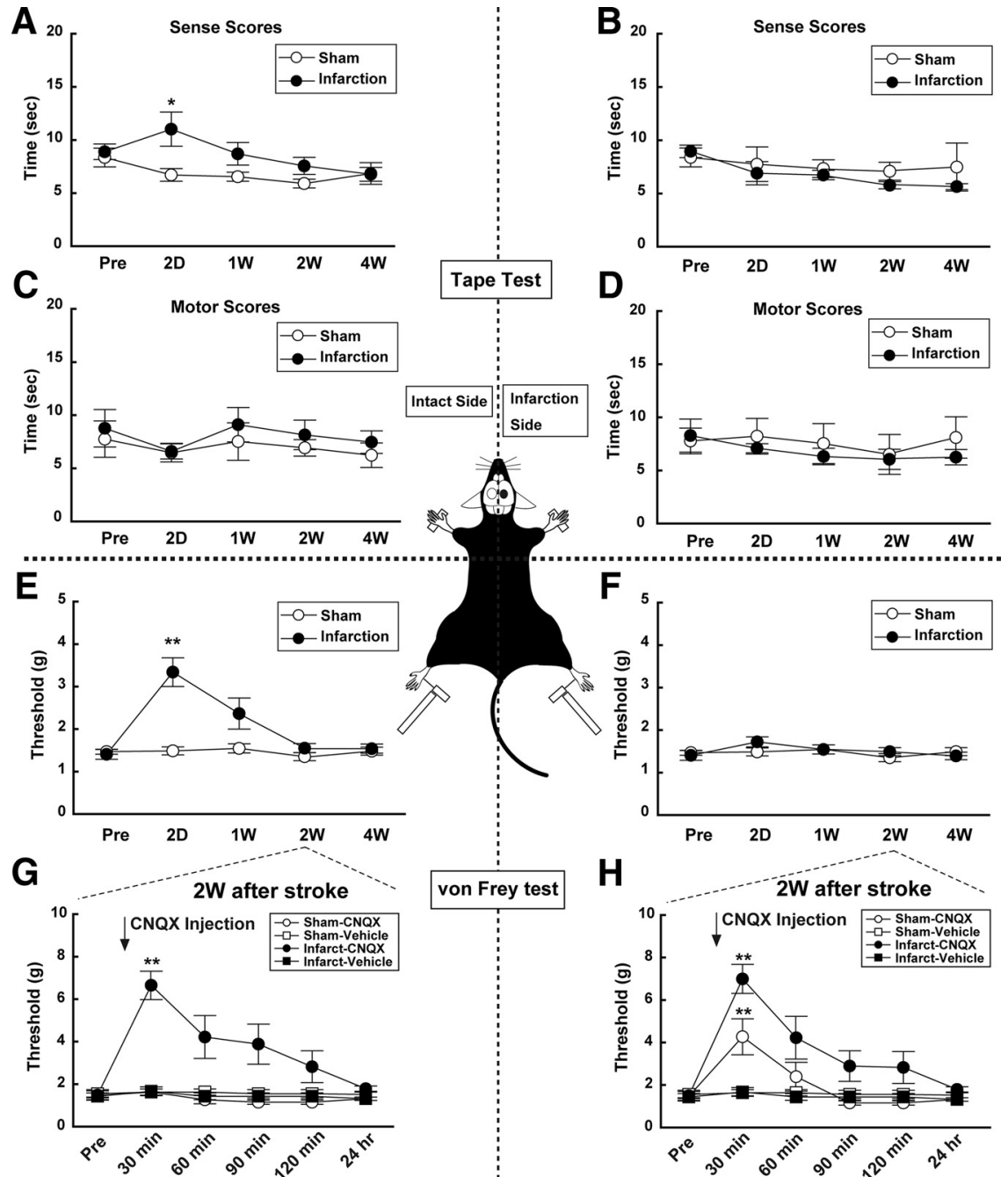

Figure 4. Behavioral tests reveal a recovery of somatosensory function by 1 week after stroke. $A-D$, Responses to the "tape test" indicate the ability to detect (Sense) and respond (Motor) to the sensory stimulus. $A, B$, Sensory responses to stimulation of the left $\operatorname{limbs}(\boldsymbol{A})$ were impaired at $2 \mathrm{~d}$, but recovered to those before stroke (Pre) by $1-4 \mathrm{~W}$. The sensory response to right limb stimulation $(\boldsymbol{B})$ was unaffected by the infarct to the right SSC. $\boldsymbol{C}, \boldsymbol{D}$, Motor function (see supplemental Methods, available at www.jneurosci.org as supplemental material) was not affected by infarction in the SSC. $\boldsymbol{E}, \boldsymbol{F}$, The von Frey hair test also revealed a selective decrease in response to stimulation of the left limb, which recovered to the control levels by $2-4 W . G, H$, Injection of CNQX into the left (intact) hemisphere resulted in a loss of sensory function in response to left limb stimulation at $2 \mathrm{~W}$ only in stroke mice $(\boldsymbol{G})$. The response to right limb (contralateral) stimulation $(\boldsymbol{H})$ was impaired by CNQX both in stroke and sham mice. The injection of vehicle did not affect sensory function. Thus, the left SSC can process bilateral sensory information following infarction of the right SSC. Statistical comparison was performed by Bonferroni test.

dritic spines in the left SSC, as it was not observed in response to a focal infarction to the right hemisphere visual cortex (Fig. 2). Previously reported, the turnover of mushroom spine, especially the gain of spine, was continuously enhanced in peri-infarction area for 6 weeks following the acute loss of the spine (Brown et al., 2007; Zhang and Murphy, 2007). In this study, interestingly, the turnover rate (gain/loss) was significantly increased only at 1 week after stroke (Fig. 2 B). However, the number of mushroom spines (density of mushroom spine) appeared unchanged (supplemental Table S3, available at www.jneurosci.org as supplemental material) because the number of gain and loss was approximately similar. These results suggested that the mechanism of recovery from stroke is different between peri-infarction area and contralateral (intact) area.

In the intact brain, mushroom spines are very stable neuronal structures, being maintained for more than a month or even for a year (Grutzendler et al., 2002; Trachtenberg et al., 2002). Mushroom spines along a dendrite are induced by focal and repetitive activation of excitatory inputs during the induction of long-term potentiation of synaptic transmission (Engert and Bonhoeffer, 1999; Maletic-Savatic et al., 1999; Matsuzaki et al., 2004). Thus, a loss of mushroom spine stability (Fig. 2) might be induced by continuous increases of basal neuronal activity (Fig. $1 B, C$ ) and the afferent activity conducting sensory information from ipsilateral periphery (Fig. $1 D, E$ ). The transient increase of this plasticity suggests a critical period of neuronal remodeling following stroke, during which there is a loss of stability and increase of circuit remodeling. This plasticity may result in the establishment of new neuronal circuits in the intact SSC and modulate the basal brain activity. Functional change of silent synapses might also contribute to the achievement of new functional circuits after stroke (Kerchner and Nicoll, 2008).

We showed that novel neuronal circuits mediating the response to sensory stimulation of the left (ipsilateral) limbs developed in the left (intact) SSC over the first weeks after focal infarction and became established by $4 \mathrm{~W}$ by using CSD analysis technique (Fig. 3). CSD analysis provides a functional mapping of neuronal circuit activity (Haberly and Shepherd, 1973; Nicholson and Freeman, 1975; Chapman et al., 1998) with a higher temporal resolution of electrical circuits' events (Mitzdorf, 1985) as well as their spatial distribution (see also supplemental Fig. S4, available at www.jneurosci.org as supplemental material). This time course of the gradual appearance of this sink/ source pattern is compatible with that of the recovery of the behavioral responses to sensory stimulation applied to the ipsilateral limbs (Fig. 4). These results suggested the possibility that the transient increase of turnover ( $\sim 1$ week after stroke) (Fig. 2$)$ induced the remodeling of the neuronal circuit in intact hemisphere. This change gradually enables the neuronal circuit to process the bilateral somatosensory information (between 1 and 4 weeks after stroke) (Fig. 3), resulting in long-lasting functional recovery (Fig. 4; see also supplemental Fig. S5, available at www.jneurosci.org as supplemental material).

In conclusion, we observed a critical period of structural plasticity within intact hemisphere that preceded the establishment of new neuronal circuits that are likely to mediate this functional compensation. An early onset of rehabilitation following strokes is critical for functional recovery both in clinical and experimental study (Johansson, 2000; Biernaskie et al., 2004; Ludlow et al., 2008) as well as the spine plasticity (Johansson and Belichenko, 2002). Our data suggest that effective treatment protocols occurring within this critical period $(\sim 1$ week after stroke) may most 
efficiently induce remodeling of neuronal circuits and enhance functional recovery.

\section{References}

Biernaskie J, Chernenko G, Corbett D (2004) Efficacy of rehabilitative experience declines with time after focal ischemic brain injury. J Neurosci 24:1245-1254.

Brown CE, Li P, Boyd JD, Delaney KR, Murphy TH (2007) Extensive turnover of dendritic spines and vascular remodeling in cortical tissues recovering from stroke. J Neurosci 27:4101-4109.

Bütefisch CM, Kleiser R, Seitz RJ (2006) Post-lesional cerebral reorganisation: evidence from functional neuroimaging and transcranial magnetic stimulation. J Physiol Paris 99:437-454.

Calautti C, Baron JC (2003) Functional neuroimaging studies of motor recovery after stroke in adults: a review. Stroke 34:1553-1566.

Cao Y, D'Olhaberriague L, Vikingstad EM, Levine SR, Welch KM (1998) Pilot study of functional MRI to assess cerebral activation of motor function after poststroke hemiparesis. Stroke 29:112-122.

Carmichael ST (2003) Plasticity of cortical projections after stroke. Neuroscientist 9:64-75.

Chapman CA, Trepel C, Ivanco TL, Froc DJ, Wilson K, Racine RJ (1998) Changes in field potentials and membrane currents in rat sensorimotor cortex following repeated tetanization of the corpus callosum in vivo. Cereb Cortex 8:730-742.

Chollet F, DiPiero V, Wise RJ, Brooks DJ, Dolan RJ, Frackowiak RS (1991) The functional anatomy of motor recovery after stroke in humans: a study with positron emission tomography. Ann Neurol 29:63-71.

Cramer SC, Nelles G, Benson RR, Kaplan JD, Parker RA, Kwong KK, Kennedy DN, Finklestein SP, Rosen BR (1997) A functional MRI study of subjects recovered from hemiparetic stroke. Stroke 28:2518-2527.

Crosson B, McGregor K, Gopinath KS, Conway TW, Benjamin M, Chang YL, Moore AB, Raymer AM, Briggs RW, Sherod MG, Wierenga CE, White KD (2007) Functional MRI of language in aphasia: a review of the literature and the methodological challenges. Neuropsychol Rev 17:157-177.

Engert F, Bonhoeffer T (1999) Dendritic spine changes associated with hippocampal long-term synaptic plasticity. Nature 399:66-70.

Gonzalez CL, Gharbawie OA, Williams PT, Kleim JA, Kolb B, Whishaw IQ (2004) Evidence for bilateral control of skilled movements: ipsilateral skilled forelimb reaching deficits and functional recovery in rats follow motor cortex and lateral frontal cortex lesions. Eur J Neurosci 20:3442-3452.

Grutzendler J, Kasthuri N, Gan WB (2002) Long-term dendritic spine stability in the adult cortex. Nature 420:812-816.

Haberly LB, Shepherd GM (1973) Current-density analysis of summed evoked potentials in opossum prepyriform cortex. J Neurophysiol 36:789-802.

Honoré T, Davies SN, Drejer J, Fletcher EJ, Jacobsen P, Lodge D, Nielsen FE (1988) Quinoxalinediones: potent competitive non-NMDA glutamate receptor antagonists. Science 241:701-703.

Johansson BB (2000) Brain plasticity and stroke rehabilitation. The Willis lecture. Stroke 31:223-230.

Johansson BB, Belichenko PV (2002) Neuronal plasticity and dendritic spines: effect of environmental enrichment on intact and postischemic rat brain. J Cereb Blood Flow Metab 22:89-96.

Kerchner GA, Nicoll RA (2008) Silent synapses and the emergence of a postsynaptic mechanism for LTP. Nat Rev Neurosci 9:813-825.

Lomo T (1971) Patterns of activation in a monosynaptic cortical pathway: the perforant path input to the dentate area of the hippocampal formation. Exp Brain Res 12:18-45.

Ludlow CL, Hoit J, Kent R, Ramig LO, Shrivastav R, Strand E, Yorkston K, Sapienza CM (2008) Translating principles of neural plasticity into research on speech motor control recovery and rehabilitation. J Speech Lang Hear Res 51:S240-258.

Luhmann HJ, Mudrick-Donnon LA, Mittmann T, Heinemann U (1995) Ischaemia-induced long-term hyperexcitability in rat neocortex. Eur J Neurosci 7:180-191.

Maletic-Savatic M, Malinow R, Svoboda K (1999) Rapid dendritic morphogenesis in CA1 hippocampal dendrites induced by synaptic activity. Science 283:1923-1927.

Matsuzaki M, Honkura N, Ellis-Davies GC, Kasai H (2004) Structural basis of long-term potentiation in single dendritic spines. Nature 429:761-766.

Mitzdorf U (1985) Current source-density method and application in cat cerebral cortex: investigation of evoked potentials and EEG phenomena. Physiol Rev 65:37-100.

Neumann-Haefelin T, Hagemann G, Witte OW (1995) Cellular correlates of neuronal hyperexcitability in the vicinity of photochemically induced cortical infarcts in vitro. Neurosci Lett 193:101-104.

Nicholson C, Freeman JA (1975) Theory of current source-density analysis and determination of conductivity tensor for anuran cerebellum. J Neurophysiol 38:356-368.

Que M, Witte OW, Neumann-Haefelin T, Schiene K, Schroeter M, Zilles K (1999) Changes in GABA(A) and GABA(B) receptor binding following cortical photothrombosis: a quantitative receptor autoradiographic study. Neuroscience 93:1233-1240.

Reinecke S, Dinse HR, Reinke H, Witte OW (2003) Induction of bilateral plasticity in sensory cortical maps by small unilateral cortical infarcts in rats. Eur J Neurosci 17:623-627.

Schiene K, Bruehl C, Zilles K, Qü M, Hagemann G, Kraemer M, Witte OW (1996) Neuronal hyperexcitability and reduction of GABAA-receptor expression in the surround of cerebral photothrombosis. J Cereb Blood Flow Metab 16:906-914.

Trachtenberg JT, Chen BE, Knott GW, Feng G, Sanes JR, Welker E, Svoboda $\mathrm{K}$ (2002) Long-term in vivo imaging of experience-dependent synaptic plasticity in adult cortex. Nature 420:788-794.

Wake H, Moorhouse AJ, Jinno S, Kohsaka S, Nabekura J (2009) Resting microglia directly monitor the functional state of synapses in vivo and determine the fate of ischemic terminals. J Neurosci 29:3974-3980.

Ward NS (2007) Future perspectives in functional neuroimaging in stroke recovery. Eura Medicophys 43:285-294.

Weiller C, Isensee C, Rijntjes M, Huber W, Müller S, Bier D, Dutschka K, Woods RP, Noth J, Diener HC (1995) Recovery from Wernicke's aphasia: a positron emission tomographic study. Ann Neurol 37:723-732.

Zhang S, Murphy TH (2007) Imaging the impact of cortical microcirculation on synaptic structure and sensory-evoked hemodynamic responses in vivo. PLoS Biol 5:e119. 